\title{
Does Exists Some Relationship between Restoration and Hydrology of Forests Ecosystems?
}

\author{
Kelly Cristina Tonello ${ }^{1 *}$ and Herly Carlos Teixeira Dias ${ }^{2}$ \\ ${ }^{1}$ Federal University of São Carlos, Sorocaba, Brazil \\ ${ }^{2}$ Federal University of Viçosa, Brazil
}

Submission: December 26, 2017; Published: February 01, 2018

"Corresponding author: Kelly Tonello, Department of Environmental Science, Hydrology of Forest Ecosystems, Federal University of São Carlos, Sorocaba, São Paulo, Brazil, Email: kellytonello@yahoo.com

\begin{abstract}
For many years, the relationship between forests and water has been of interest to scientists around the world. It is well known that forests influence the hydrological cycle and consequently, influence water resources. This work aims to introduce a discussion about the relation of the forest to the availability of water in the soil and its effect on the recharge of water in the soil. The presence of forest formations enables rainwater catchment, partitioning, and well-balanced distribution across forest compartments. Forest cover favors the occurrence of infiltration, percolation, and storage of water in the soil. It also reduces the occurrence of surface runoff and erosive processes, since vegetation contributes to the aggregation of soils with high organic matter, humidity, and active microbial biomass. Some intriguing questions, however, remain unaddressed. In which moment along vegetation development does forest restoration contribute to soil hydric maintenance? Moreover, shifting the research focus to another scale, in which moment and how does forest restoration interfere with water balance in a given river basin? These are the questions that motivated us to conduct the present study, in order to provide a scientific basis for the discussion.
\end{abstract}

Keywords: Forest hydrology; Net precipitation; Groundwater

\section{A little of History}

From beliefs rooted in popular culture, many people associate the presence of water in rivers and reservoirs with the goodness of St. Peter, popularly known as the ruler of the rains. But would it really be that simple? Will the increase and decrease in the amount of water available on the surface of the earth be only associated with rainfall?

Doubts over the origin and conservation of water from the springs and rivers were already worrying Greek philosophers, who devoted much time to establishing hypotheses to explain the phenomenon. Aristotles and Vitruvius (382BC) believed that groundwater derived, for the most part, from the infiltration of rainwater into the soil. These philosophers said that the mountains would be the ideal places for the preservation of the waters. This is because they receive a large amount of rain and snow and do not allow large losses by evaporation, because the presence of the forest cover decreases the entrance of the solar rays inside the same, and thus, the water of the the surface water and the snow cover remain longer due to the dense forest.

However, the explanations were not unanimous and remained controversial over the years. Before the end of the seventeenth century, for example, it was believed that spring water could not originate from the rains because it was thought that the volumes would not be sufficient and that the earth was too impervious to allow water infiltration and percolation of rain.

Throughout the eighteenth and nineteenth centuries, as scientific knowledge still failed to respond satisfactorily to questions about the origin and conservation of water on the earth's surface, government agencies - based on speculation and personal opinions - began to create "protective forests" , considering that the forests were being cut down to give way to agriculture, and that, following the example of the Greek philosophers, the importance of natural reserves in the maintenance of water resources had already been defended.

In the 1930s, in the Wagon-Wheel Gap, in the state of Colorado, two micro-basins, adjacent and forested, were instrumented in the study of the origin and conservation of water. for the accurate measurement of rainfall and water production (dewatering). During an initial period, in which both catchment remained with their forest cover unchanged, these two hydrological processes were monitored, in order to 
obtain a calibration equation of one catchment according to the other. At the end of the calibration period, one area was cleared from the forest, while the other remained unchanged. After the experimental treatment, measurements were prolonged in both basins for a further number of years. With the cut of the forest, the loss of water has been reduced by the sweating process, after all, the forests also consume water. However, the exposed and unprotected soil became poor and compacted, making it difficult to infiltrate rainwater inside it.

From this experience, the role of forests in the conservation of water resources became more evident, since in an equilibrium system, with the preservation of the forest cover, the water withdrawal and replenishment happen in a tuned way and all losses are compensated. With the preservation of forests - which open natural canals by the growth of their roots and interaction with soil microorganisms - the soil remains in an ideal condition for the retention of water in the volumes necessary for the conservation of the springs.

By 1950, all units of the American Forest Service had a sector of experimental catchments. At the time, there were more than 150 experimental micro-forests in the United States, and by 1970 more than 2000 research papers had been published. Of the certainties: of all the direct influences of the forest, its influence on the rivers and on the regularity of their flows is the most significant for the human economy.

\section{About Forest and Water}

Studies have demonstrated, for instance, that plant roots, either living or dead, play a role in channelling and directing steam flow water through soil, thus indicating the occurrence of a hydrological response to rainfall events [1-3].

[4-6] have presented an in-depth discussion on the forestwater-climate relationship. Another important approach was made by the UN Food and Agriculture Organization (FAO), who organized the "Forests and Water a Five-Year Action Plan", launched in Durban during the 14th World Forestry Congress. The plan calls for the tangible integration of science, policy, and practice related to forest-water interactions. Among its various goals, it aims to highlight the importance of both forest and water management $[7,8]$.

The fact is that areas with the presence of vegetation and of soils in good aggregation conditions do not have the same effects on the hydrological cycle of a river basin $[3,8,9]$. Still, degradation of natural environments as well as urbanization of natural landscapes continues to increase, and both interfere in the status and availability of water in the several compartments of the soil-plant-atmosphere system $[10,11]$.

Ecological restoration is defined as the science, practice and art of assisting and managing the recovery of the ecological integrity of ecosystems, including maintaining a minimum level of biodiversity and variability in the structure and functioning of ecological processes, considering their ecological, economic and social values [12]. According to [13], this definition provides an ecosystemic vision of the ecological restoration process. However, due to the high complexity of the biological interactions among species and the relationships between species and abiotic factors, establishing a practical approach remains a great challenge. This fact reveals a lack of knowledge on the complex interactions that regulate these ecosystems.

As a result of this scarcity of knowledge and the consequent lack of applied methods to insert this kind of ecosystemic vision in ecological restoration practices, all current focus of ecological restoration is almost exclusively directed toward the biological component of degraded ecosystems [13]. However, the compartmentalized and individualized study of the parts of these ecosystems, e.g. an approach focusing solely on the structure of the tree community without considering its interaction with the other plant life forms, fauna or physical environmental factors, does not suffice to conclude on the resilience and/or state of equilibrium of the ecosystem [14-16].

With the ecological restoration of degraded lands, it is expected that along their development the forests therein might act in catching and distributing rainwater, thus making water available to the soil and ultimately contributing to the occurrence of infiltration, percolation, and aquifer recharge. To date, little research has included hydrological dynamics as a factor to be analyzed in areas undergoing restoration. Thereby, the precise moment of forest restoration development in which there is an effective contribution to the maintenance of soil water remains unknown. Additionally, little is still known on the ecological and hydrological influences in which the changes that arise from restoration result. Thus, comprehending the relationships between rainwater and vegetation during each stage of restoration is of high relevance, since the maintenance of surface and underground water reserves of river basins ultimately depends on those relationships $[17,18]$.

It is known that plant formation, as well as vegetation density, plays an important role in the distribution of rainwater among the components of the ecosystem, being essential for the maintenance of several hydrological aspects and stability of the balance water.

In the occurrence of a rain event on a forest fragment (Figure 1), the first rainfall hydrologic process to occur is Interceptation (I), which corresponds to the water intercepted by the forest canopy. This water is retained in the canopy and returns to the atmosphere through evaporation. The water that then crosses the canopy and follows towards the ground, is denominated like Through fall (Tf). The Tf, along with the portion of water that also reaches the soil but by Stemflow (Sf) of the arboreal individuals of the forest fragment, constitutes the Net Precipitation (NP). 


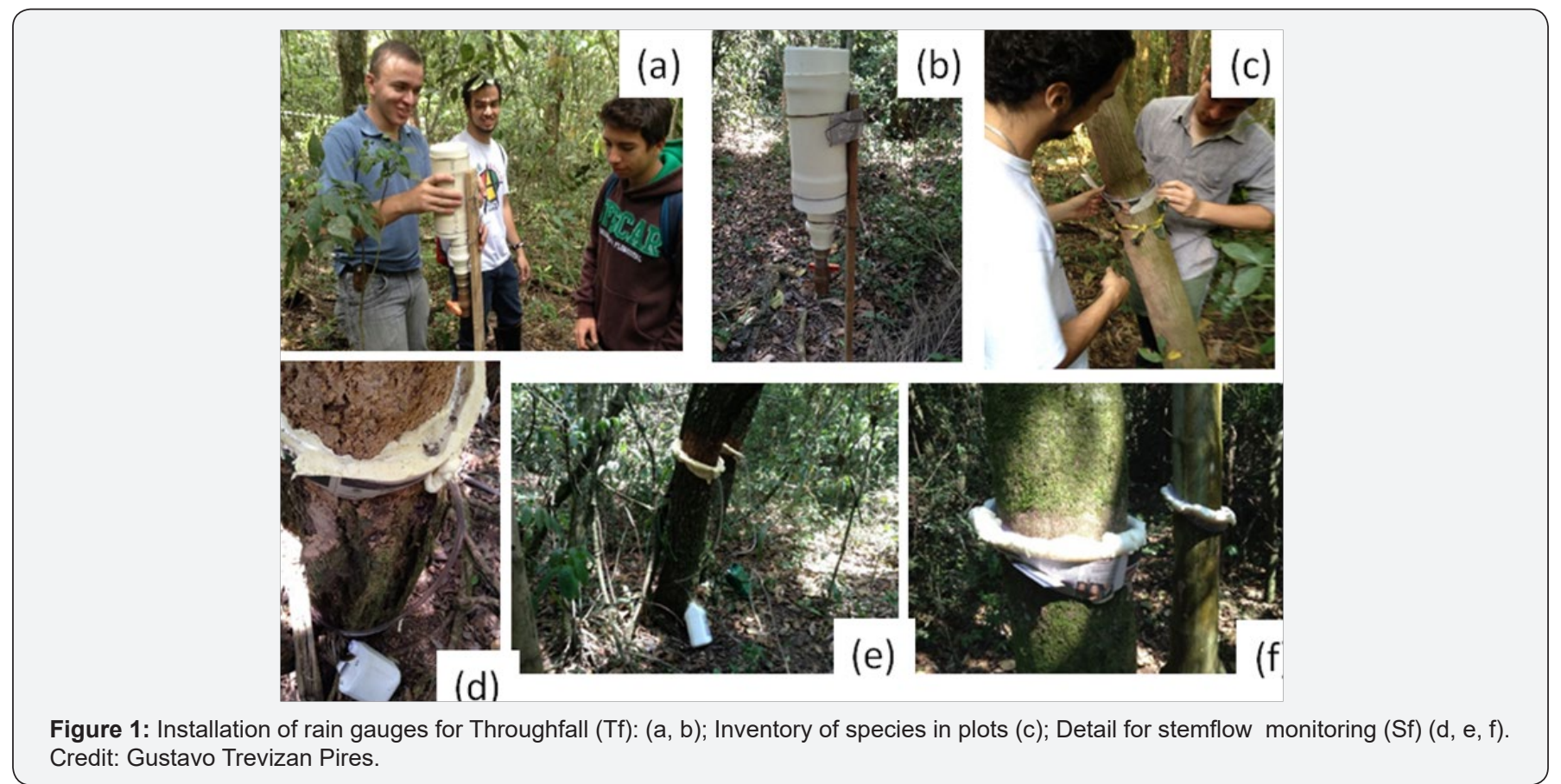

When NP reaches the ground, what is expected is that this water infiltrates the same and percolate to compose the groundwater. This, in turn, is who maintains the springs, rivers, lakes, and so on.

But, NP will only infiltrate if the soil has the conditions for this process to occur. The soil structure must be adequate, not compacted. The importance of forests in this case is associated with the growth and development of their roots, which form channels through which water infiltrates and walks underground. In addition, litter, the organic matter formed by the decomposition of plant material, provides a protective layer to the soil, in order to avoid losses of water by evaporation and also the development of microorganisms beneficial to the recovery of that soil.

If the soil is not able to receive NP, surface runoff will occur. The runoff is synonymous of "lost water", precisely because it does not contribute to the recharge of water in the soil. And, depending on some factors such as its volume and slope of the terrain, can cause damages: erosion, silting, loss of soil nutrients, among others.

This is how the Forest-Water relationship is done. But, from the hydrological point of view, at what stage during the development of the vegetation does the forest restoration contribute to soil water maintenance? How will it interfere with the water balance of a watershed?

The presence of vegetation cover has a close relationship with the hydrological cycle of a river basin. It plays an important regulatory role in the context of the water balance by promoting the abstraction and distribution of rainwater within the compartments of the system, assisting in the regulation of soil water flow, as well as in the process of water supply for aquifer recharge $[4,19,20]$.

However, increasing human interference with natural ecosystems has been increasing in area and degree of degradation of natural environments. Due to one or a set of factors that cause changes of great impact, the degradation of ecosystems restricts or impedes the dynamics, functioning and sustainability of different ecosystems and compartments, including the hydrological cycle. In the case of new human demands linked to the current development model, this situation is exacerbated, bringing even greater losses to vegetation, soil and water resources, increasing degradation [21] and recharge groundwater.

Knowing the characteristics of the hydrological balance, as well as the hydrological processes in the ecosystem, is essential [22] to understand its operation, thus allowing to define the most adequate and efficient management practices both from an ecological and economic point of view. However, little is known about the ecological and hydrological influences that the changes resulting from regeneration entail, being relevant the understanding of the relationships between rainwater and vegetation among the different stages of the restoration, since, in the last instance, it is this relation which depend on the groundwater and surface water reserves of much of the country [23].

\section{Final Considerations}

Rainwater corresponds to the entrance of water into the forest ecosystem, which is an important component for soil water maintenance and groundwater recharge due to the benefits already mentioned. 
However, the forest also consumes water. But it also promotes equilibrium in the inflow and outflow of water in the river basin. If the soil is not suitable to provide water infiltration, it will seep out. The forest manages to recover this soil in depth, but also needs water to develop. And the question continues: at what point in the development process do we have the balance? After 1 or 2 years of forest restoration? Or after 10 years? We do not know ... relationships are not simple and depend on a number of factors intrinsic or not to that environment. But despite this, we must move forward and seek answers to the questions.

\section{Acknowledgements}

We would like to thank the CNPq.

\section{References}

1. Ellison D, Morris CD, Locatelli B, Sheil d, Cohen J, et al. (2017) Trees, forests and water: Cool insights for a hot world. Global Environmental Change 43: 51-61.

2. Neary DG, Ice GG, Jackson CR (2009) Linkages between forest soils and water quality and quantity. Forest Ecology and Management 258: 2269-2281.

3. Schwärzel K, Ebermann S, Schalling N (2012) Evidence of double funneling effect of beech trees by visualization of flow pathways using dye tracer. Journal of Hydrology 471: 184-192.

4. Andréassian (2004) Waters and forests: from historical controversy to scientific debate. Journal of Hydrology 291: 1-27.

5. Bruijnzeel LA (2004) Hydrological functions of tropical forests: not seeing the soil for the trees? Agric Ecosyst Environ 104: 185-228.

6. FAO (2013) Forests and Water: International Momentum and action. p. 75.

7. FAO (2015) Forest and Water - A Five-Year Action Plan. FAO, Rome, Italy.

8. Freitas JPO, Dias HCT, Silva E, Tonello KC (2016) Net precipitation in a semideciduous forest fragment in Viçosa city. MG Rev Árvore 40(5): 793-801.

9. Lorenzon AS, Dias HCT, Leite HG (2013) Precipitação efetiva da chuva em um fragmento florestal com diferentes estágios de regeneração. Revista Árvore Viçosa 37(4): 619-627.

10. Carvalho APV, Dias HCT, Tonello KC, Paiva HN (2016) Net precipitation and recharge of groundwater in riacho fundo watershed, FelixlândiaMG. Revista Árvore 40(6): 965-971.
11. Holder CD, Gibbes C (2016) Influence of leaf and canopy characteristics on rainfall interception and urban hydrology. Hydrological Sciences Journal 66(2): 2017.

12. Society for Ecological Restoration (2004) The SER International Primer on Ecological Restoration. Version 2. Society for Ecological Restoration International Science and Policy Working Group.

13. Rodrigues RR, Brancalion PHS, Isernhagen I (2009) Pacto para a restauração da Mata Atlântica: referencial dos conceitos e ações de restauração florestal. ( $1^{\text {st }}$ edn), São Paulo, Instituto Bio Atlântica, Brazil, 1: $14-23$.

14. Folke C, Carpenter S, Walker B, Scheffer M, Elqvist T, et al. (2004) Regime shifts, resilience, and biodiversity in ecosystem management. Annual Review of Ecology, Evolution and Systematics 35: 557-581.

15. Lugo A, Silver WL, Colón SM (2004) Biomass and nutrient dynamics of restored neotropical forest. Water, air and soil pollution: focus 4(2-3): 731-746.

16. Suding KN, Gross KL, Houserman GR (2004) Alternative states and positive feedbacks in restoration ecology. Trends in Ecology and Evolution 19(1): 46-53.

17. Bosch JM, Hewlett JD (1982) A Review of catchment experiments to determine the effect of vegetation changes on water yield and evapotranspiration. Journal of Hydrology 55(1): 3-23.

18. Honda EA, Mendonça AH, Durigan G (2015) Factors affecting the stemflow of trees in the Brazilian Cerrado. Ecohydrol 8(7): 1351-1362.

19. Arcova FCS, Cicco V, Rocha PAB (2003) Precipitação efetiva e interceptação das chuvas por floresta de mata atlântica em microbacia experimental em Cunha-São Paulo. Revista Árvore, Viçosa-MG, 27(2): 257-262.

20. Porporato A, Rodriguez-Iturbe I (2002) Ecohydrology - a challenging multidisciplinary research perspective. Hydrological Sciences Journal 47(5): 811-821.

21. Bradshaw AD (2002) Introduction and philosophy. In: Perrow MP, Davy AJ (Eds.), Handbook of ecological restoration. Cambridge University Press, Cambridge, USA, 1: 4-9.

22. Honda (2013) Repartição da água da chuva sob o dossel e umidade do solo no gradiente fisionômico da vegetação do Cerrado. Tese de doutorado-Programa de Pós-Graduação em Ciências da Engenharia Ambiental e Área de Concentração em Ciências da Engenharia Ambiental, Escola de Engenharia de São Carlos da Universidade de São Paulo, São Carlos, Brazil, pp. 183.

23. Arcova FCS, Cicco V (1997) Características do deflúvio de duas microbacias hidrográficas no Laboratório de Hidrologia Florestal Walter Emmerich, Cunha-SP. Revista Instituto Florestal de São Paulo 9(2): 153-170.

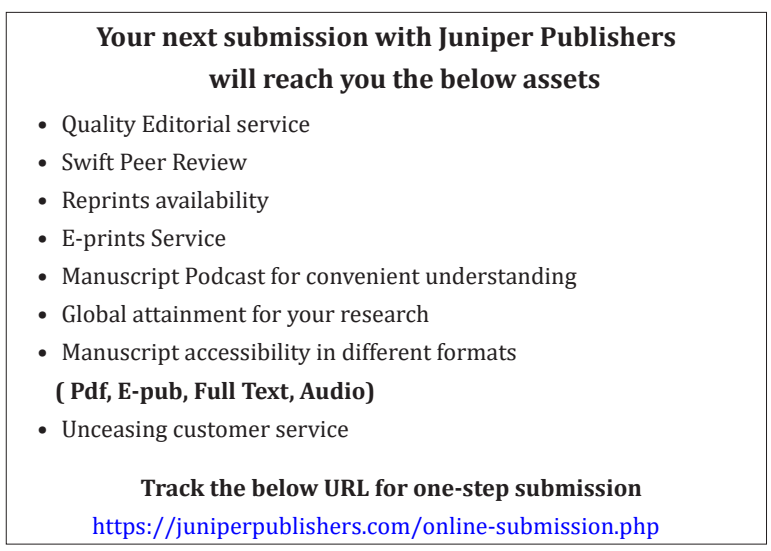

